\title{
Fertility status of Magnaporthe grisea populations from finger millet
}

\author{
R.K. Srivastava ${ }^{1}$, R.P. Bhatt ${ }^{2}$, B.B. Bandyopadhyay ${ }^{3}$ and J. Kumar ${ }^{1}$ \\ ${ }^{1}$ Dept. of Plant Pathol., G.B.P.U.A \&T Pantnagar, U.S. Nagar, Uttarakhand- 263 145, India \\ ${ }^{2}$ Dept. of Botany, H.N.B. Garhwal Univ., Srinagar (Garhwal) Uttarakhand-246 174, India \\ ${ }^{3}$ Dept. of Genet. \& Plant Breeding, G.B.P.U.A \& T Hill Campus Ranichauri, Tehri Garhwal Uttarakhand- 249 199, India \\ rikheshs@gmail.com; rajendrapbhatt@hotmail.com; bbbandyopadhyay@rediff.com; jkumar56@gmail.com
}

\begin{abstract}
Two hundred twenty nine isolates of Magnaporthe grisea were collected from finger millet cultivars at 14 locations in north India (Uttarakhand) and two locations in south India (Tamilnadu \& Karnataka). Each isolate was tested for the mating types (Male fertile and female sterile) using standard fertile testers. Per cent isolates that neither mated nor produced perithecia was high among isolates collected from south India than those from Uttarakhand. Male fertile and hermaphrodite isolates from cooler region showed greater efficiency to produce perithecia. Results revealed that distribution of mating type varied with geographical region. Male fertile and female sterile isolates segregated in 1:1 ratio among field isolates collected from both north and south India. Field isolates from north India showed equal probability of getting male fertile, female sterile and hermaphrodite isolates, which suggested that probability for sexual reproduction in the population of $M$. grisea existed in nature in the central Himalayas of India.
\end{abstract}

\section{Keywords: Fertility, Magnaporthe grisea, Perithecia}

\section{Introduction}

Sexual dimorphism is rare in fungi and the term mating type is used to distinguish individuals, which are morphologically identical but self-incompatible. Sexual compatibility in heterothallic ascomycetes is determined by the presence of two alleles (idiomorphs) at a single mating type locus and two strain of opposite mating types produce ascospores (Glass \& Kuldau, 1992). The mating and sexual recombination in natural populations of fungal pathogens provides mechanism for generating variation through meiosis that results from independent assortment of chromosomes and recombination within chromosomes produced new genotypes (Miligroom, 1996). The ability of $M$. grisea isolate to produce perithecia indicates a complex phenotype (Valent et al., 1991), and mating ability is an excellent criterion for examining the relationship among isolates of the fungus. Kumar and Zeigler (1995) reported the occurrence of fertile blast isolates from finger millet in central Himalayan hills of Uttarakhand and showed differences in degree of sexual compatibility between $M$. grisea isolates from different hosts. Valent et al. $(1986,1991)$ demonstrated that $M$. grisea exhibited wide range of fertility ranging from total sterility (inability to that field isolates mate with another strain), through female sterile (ability to mate only as a male) to full fertility (ability to mate either male or female). It is, therefore, presumed that ragi blast pathogen possesses a broad spectrum of variability determined possibly by genetic and environmental differences. Nonavailability of basic information about the distribution of mating type and fertility status of $M$. grisea impedes the progress of genetic study on variability of blast pathogen existing in nature and restrict the process of development of suitable finger millet breeding lines to combat the menace of blast disease prevalent in any region. In the present investigation, fertility status and distribution of mating type of $M$. grisea were compared among the isolates collected from finger millet growing regions in Uttarakhand hills and parts of south India.

\section{Materials and methods Collection of isolates}

Two hundred twenty nine isolates of $M$. grisea were collected from Uttarakhand (14 locations) and Tamilnadu (2 locations) and Karnataka (2 locations), in India. Isolation and maintenance of isolates

Leaves with discrete blast lesions were cut in to small pieces of about $5 \mathrm{~cm}$ length and saturated in distilled water for $2 \mathrm{hrs}$. The steeped leaf pieces were incubated in a humid chamber at $28^{\circ} \mathrm{C}$ for $24 \mathrm{hrs}$ to induce sporulation. The spore mass from individual lesion was streaked on $4 \%$ water agar, incubated for $12 \mathrm{hrs}$ at $25^{\circ} \mathrm{C}$ and single germinating conidium was transferred to ragi yeast lactose agar (RYLA; containing $20 \mathrm{~g} / \mathrm{l}$ ground ragi powder, $20 \mathrm{~g} / \mathrm{l}$ agar, $5 \mathrm{~g} / \mathrm{l}$ lactose and $1 \mathrm{~g} / \mathrm{l}$ yeast extract) slants. Colonies were grown at $28^{\circ} \mathrm{C}$ and stored on filter paper discs at $-20^{\circ} \mathrm{C}$ as described by Valent et al. (1986).

\section{Determination of mating type}

Mating type was determined by pairing each unknown $M$. grisea isolate with two standard testers. The two testers, VII739 (hermaphrodite, MAT1-2) and VII769 (male fertile, MAT1-1) isolated from finger millet and foxtail millet,, respectively produced numerous perithecia when mated with isolates of opposite mating type (Kumar \& Zeigler, 1995).

\section{Crossing method}

Crosses were made by pairing agar blocks, cut from the margins of growing M. grisea colonies, about $3 \mathrm{~cm}$ apart on RYLA plates (Fig1). The agar plates were sealed with parafilm at $28^{\circ} \mathrm{C}$, incubated in dark for three to four days, and then placed under continuous white fluorescence light at $22^{\circ} \mathrm{C}$. After 15 days of incubation, perithecia were examined at the junction of two opposing isolates.
Research article

Clndian Society for Education and Environment (iSee)

\section{"Magnaporthe grisea"} http://www.indjst.org
Srivastava et al. Indian J.Sci.Technol. 


\section{Assessing fertility of $M$. grisea isolates}

Fertility of $M$. grisea isolates was assessed by the capacity to form perithecia asci and ascospore. The number of perithecia formed per $5-\mathrm{mm}^{2}$ agar surfaces was taken as the measure of fertility in each cross (Fig.1). Based on the modified method of Leung and Williams (1985) and Leung et al (1988), isolates were classified belonging to high ( $>30$ perithecia/ $5 \mathrm{~mm}^{2}$ ), intermediate $\left(15-25\right.$ perithecia/ $\left.5 \mathrm{~mm}^{2}\right)$, and low $\left(15\right.$ perithecia/ $\left.5 \mathrm{~mm}^{2}\right)$ fertility groups. Isolates not producing perithecia were classified as sterile. All isolates that produced perithecia were reassessed for fertility.

Fig. 1. A- In vitro production of perithecia when mated with standard fertile tester (finger millet) VII739 X VII769 (foxtail millet). B-Number of perithecia formed per $5 \mathrm{~mm} 2$ agar surface 20X. C-Perithecium releasing mature asci 20X. D-Ascus in tetrad form 100X

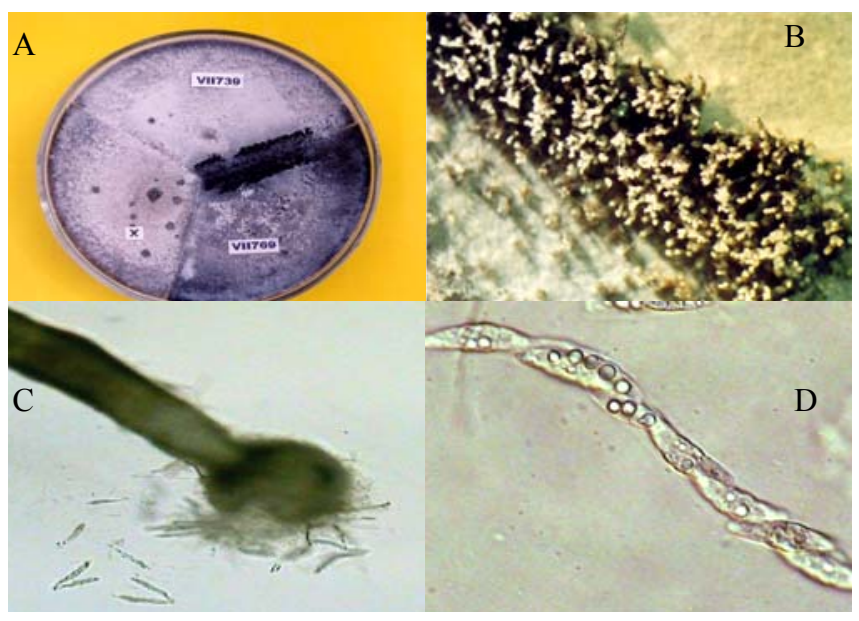

\section{Ascospore isolation}

Mature perithecia were examined under a stereo binocular microscope. The bulbous base shape and larger size of mature perithecia distinguished them from the immature ones (Fig.1). Mature prithecia were placed on $4 \%$ water agar medium and pressed gently with fine needle to release asci. The remnants of perithecia were removed. Care was taken not to scratch the smooth surface of the water agar media so that visibility for picking single ascospores was not hindered. A glass needle with fine and curved tip was used to separate asci from the ascal fan. Free ascospore germinated on water agar medium at $28^{\circ} \mathrm{C}$. After 2-6 hour germinated ascospores were transferred to RYLA slants and incubated at $28^{\circ} \mathrm{C}$ until analysis.

\section{Pathogenicity assay}

A total of 27 isolates of $M$. grisea, which included 25 single ascospore progenies and two parent isolates, were tested for pathogenicity and virulence to finger millet (cv $\mathrm{K}-7$ ) and foxtail millet (local cv). The experiment was conducted under controlled conditions in a greenhouse, when optimal conditions $\left(25^{\circ} \mathrm{C}\right.$ with alternate light and dark period) for blast disease development prevailed. Seeds of each cultivar were sown in plastic disposable cups $(6 \times 6 \times 6 \mathrm{~cm})$ filled with sterilized soil. Seedlings were thinned at the two-leaf stage. Cups were arranged in random block design for the experiment. Individual trays containing growing seedlings were covered with polythene hoods to avoid cross contaminations. An uninoculated batch of plants maintained under similar conditions served as check. For mass multiplication of inoculum, actively growing mycelia were macerated and seeded onto RYLA plates. This was followed by incubation for 5 days at $27^{\circ} \mathrm{C}$ in dark and exposure to fluorescent light at $25^{\circ} \mathrm{C}$ for 3-4 days. A spore concentration of $5 \times 10^{5}$ was maintained for inoculation. Twenty one- day- old plants were sprayed with 75-100 ml of spore suspension $\left(5 \times 10^{5}\right)$ and incubated for $36 \mathrm{hrs}$ in dark at $25^{\circ} \mathrm{C}$ and subsequently removed to mist chamber at $30^{\circ} \mathrm{C}$ (day) and $25-28^{\circ} \mathrm{C}$ (night) temperature regimes. Symptoms were recorded after seven days following the scale: $0=$ No infection; $1=$ Dark specks, resistant type lesion without sporulation; $2=S$ mall, roundish necrotic lesion with grey center less than $1 \mathrm{~mm}$ in diameter; $3=$ Roundish lesion with 1-3mm gray center, occasionally sporulating; 4=Large sporulating and expanding lesion, grey center not more than $3 \mathrm{~mm}$ in diameter with well defined brown margins and 5=Large coalescing lesion, brown not well defined.

\section{Results}

\section{Distribution of mating types}

The distribution of mating type of $M$.grisea isolates is shown in Table 1. Of the 154 isolates collected from north India (Uttarakhand), 103 isolates showed perithecial formation with 45 isolates being male fertile and 31 female sterile while 27 isolates formed perithecia in double row at the intersection indicating hermaphroditic characteristic (Itoi et al., 1993). Of the 75 isolates from south India, 23 were male fertile and 17 were female fertile. The two mating types segregated in 1:1 ratio in isolates from both the states. In north India, male fertile, female sterile and hermaphrodite showed equal probability.

\section{Fertility of M. grisea}

Number of perithecia produced on $5 \mathrm{~mm}^{2}$ agar surface by different fertile isolates of $M$. grisea is given in Table 1 . Of the 154 isolates from north India, 87 (56.4\%) were highly fertile, $16(10.3 \%)$ produced barren perithecia and $51(33.1 \%)$ did not mate with any of the testers. Whereas, from south India, of the 75 isolates $34(45.3 \%)$ were highly fertile, $9(12.0 \%)$ produced barren perithecia and 32 $(42.6 \%)$ did not mate with any of the testers. Of the total 229 isolates, 121(90.8\%) produced highly fertile perithecia.
Research article

CIndian Society for Education and Environment (iSee)
"Magnaporthe grisea" http://www.indjst.org
Srivastava et al. Indian J.Sci.Technol. 


\section{Test of pathogenicity and virulence}

Ascospore progenies of $M$. grisea showed compatible disease reaction towards the hosts, setaria and finger millet, and lesions were of infection types 3 and 4 . The tester isolates VII 739 of finger millet origin infected only finger millet cultivars and the tester strain VII 769 of foxtail millet origin infected only foxtail millet cultivar. Lesions produced by parental isolates on compatible hosts were of infection type 4 and 5 . Thus, the ascospore isolate, while showing ability to infect both the hosts were as virulent as the parents. In a separate inoculation experiment, all the 229 field isolates of $M$. grisea were found to infect their host of origin.

\section{Discussion}

In most of the reports existing in literature, Magnaporthe grisea isolates from finger millet have been used extensively to determine the mating types of $M$. grisea collected from rice and other sources, and to describe its perfect stage. However, inadequate information is available on the fertility status of finger millet derived $M$. grisea isolates to understand the variability of fungal pathogen in India. Kumar et al. (1995) reported that $M$. grisea collected from rice showed less fertility and higher rate of incompatibility in comparison to isolates collected from non- rice sources. Viji and Gnanamanickam (1998) reported that isolates from finger millet and paragrass collected from south India (TamilNadu, Andhra Pradesh, Kerala and Karnataka) were highly fertile in terms of perithecial production when compared to rice isolates, and their backcrossing scheme indicated definite pattern of Mendelian inheritance. In this investigation, greater degree of sexual compatibility was observed among the population of $M$. grisea from finger millet isolates collected from Uttarakhand (North India) using fertile standard testers of known mating type. The distribution of mating type and fertility of isolates, variation in genetic trait conditioning sexual reproduction among the isolates was observed in the finger millet derived $M$. grisea isolates from three state viz. Uttarakhand (north India) Karnataka and Tamilnadu (south India). Results revealed that of the total 229 isolates examined from north India, 19.65 per cent were male fertile, 13.53 per cent female sterile, 11.79 per cent were hermaphrodites, 6.99 per cent showed barren asci and 18.77 per cent did not mate with the testers. Contrarily, from south India, 10.04 per cent were male fertile, 7.42 per cent were female sterile, 1.31 per cent were hermaphrodites, 3.93 per cent produced barren perithecia and 13.97 percent did not mate with any of the testers. It was, therefore, apparent that $M$. grisea isolates having origins from different parts of country behaved differently. In terms of perithecial production, M. grisea isolates appeared to be more fertile $(63.7 \%)$ when collected from non-rice host (finger millet) than rice, which showed 39.6\% fertility (Dayakar, 2000). Host association has been described as an important factor conditioning the fertility of $M$. grisea field isolates (Kolmer \& Ellingboe, 1988; Leung et al., 1988) and genetic distinctiveness of fingermillet isolates in terms of their fertility observed among the north Indian isolates in the present study conforms this. The hermaphrodites that are commonly found among finger millet isolates may account for their high fertility.

A comparison of fertility status of the isolates from north (fertile 56.49\%; infertile $33.1 \%$ ) and south India (fertile $45.3 \%$; infertile $46.2 \%$ ) revealed that field isolates of north India were genetically close and compatible to both the tester (VII739; VII769) used in this investigation possibly because both tester were obtained from finger millet and foxtail millet cultivars from similar climatic condition in the hills of Uttarakhand state. This suggested that genetic differences in compatibility of isolates or polymorphic behaviour of blast fungus determined the nature of mating type in population rather than unsuitable conditions for ascus formation, since under identical condition other isolates show their ability to produce ascospore (Urashima et al., 1993). A variety of genetic abnormalities, including mutation, chromosomal duplication, and heterogeneity have been described for the production of barren perithecia (Tanaka et al.,1979) during mating. Simultaneously, it could also be attributed that inability to form perithecia in some $M$. grisea isolates in sexual reproduction are related to the presence of genetic distance and maintenance of isolation by blast fungus for a long time (Silue et al.,1992). A perusal of experimental data revealed that male fertile and female sterile isolates from north and south India were found in 1: 1 ratio, which is characteristic of a randomly mating population (Miligroom, 1996). An equal probability, however, was observed among isolates from north India viz. male fertile, female sterile and hermaphrodite. This indicated that sexual recombination in north India possibly exists due to hermaphrodite. This also attributed that sexual union of blast fungus remains high in nature under cool climatic condition such as in north India. Pathogenicity studies support an earlier suggestion (Valent et al., 1986) that the ascospore are not only sexually recombinant but also possess altered pathogenicity and virulence characteristic unlike their parent isolates. Distributions of mating type, fertility, pathogenicity of $M$. grisea presented in this study indicate that sexual recombination of $M$. grisea possibly occurs at field population under natural condition. These results support an earlier view that a sexually recombinant population of $M$. grisea already exists in the central Himalayan regions of India (Kumar \& Zeigler, 1998).

\section{Reference}

1. Dayakar BV and Narayanan NN and Gnanamanickam SS (2000) Cross compatibility and distribution of mating type alleles of the rice blast fungus Magnaporthe grisea in India. Plant Dis. 84, 700-704.
Research article

CIndian Society for Education and Environment (iSee)
"Magnaporthe grisea" http://www.indjst.org
Srivastava et al. Indian J.Sci.Technol. 
2. Ellinboe $\mathrm{AH}, \mathrm{Wu} B \mathrm{BC}$ and Robertson W (1990) Inheritance of avirulence/ virulence in a cross of two isolate of Magnaporthe grisea pathogenic to rice. Phytopathol. 80, 108-111.

3. Glass NL and Kuldue GA (1992) Mating type and vegetative incompatibility in filamentous ascomycetes. Ann. Rev. Phytopathol. 30, 201-224

4. Hebert TT (1971) The perfect stage of Pyricularia grisea. Phytopathology. 61, 83-87.

5. Itoi S, Mishima T, Arase S and Nozu M (1983) Mating behavior of Japanese isolates of Pyricularia oryzae. Phytopathol. 73, 155-158.

6. Kolmer JA and Ellingboe AH (1988) Genetic relationship between fertility, pathogenecity and avirulence to rice in Magnaporthe grisea. Can.J.Bot. 66, 891-897.

7. Kumar J and Zeigler RS (1995) Mating behavior of Magnaporthe grisea from central Himalayas from India. Phytopathol. (Abstr.) 85, 1201.

8. Kumar J, Nelson RJ and Zeigler RS (1999) Population structure and dynamics of Magnaporthe grisea in the Indian Himalayas. Genetics.152, 971974.

9. Leung $\mathrm{H}$ and Williams PH (1985) Genetic analysis of electrophoretic enzymes variants, mating type, and hermaphroditism in Pyricularia oryzae Cavara. Can.J.Genet.Cytol. 27, 697-704.

10. Leung $\mathrm{H}$, Borromeo ES, Bernado MA and Nottingham $\mathrm{JL}(1988)$ Genetic analysis of virulence in the rice blast fungus Magnaporthe grisea. Phytopathol. 78, 1227-1233.
11. Milgroom MG (1996) Recombination and the multilocus structure of fungal populations. Annu. Rev. Phytopathol. 34, 457-477.

12. Silue D, Nottegham JL and Tharreau D (1992) Evidance of a gene-for gene relationship in the Oryza sativa-Magnaporthe grisea Pathosystem. Phytopathol. 82, 577-580.

13. Tanaka Y, Murata N and Kato H (1979) Behaviour of nuclei and chromosomes during ascus development on the mating between either rice strain or weeping lovegrass-strain and ragi strain of Pyricularia. Ann.Phytopathol.Soc.Japan. 45,182-191.

14. Urashima AS, Igarashi $S$ and Kato H (1993) Host range, mating type, and fertility of Pyricularia grisea from wheat in Brazil. Plant Dis.77, 1211-1216.

15. Valent B, Farrall L and Chumley FG (1991) Magnaporthe grisea genes for pathogenicity and virulence identified through a series of backcrosses. Genetics. 127, 87-101.

16. Valent B, Crawford MS, Weaver CG and Chumley FG (1986) Genetic studies of fertility and pathogenecity in Magnaporthe grisea. Iowa State J. Res. 60, 569594.

17. Yaegashi $\mathrm{H}$ and Yamada $\mathrm{M}$ (1986) Pathogenic races and mating types of Pyricularia oryzae from Soviet Union, China, Nepal, Thailand, Indonesia and Colombia. Ann. Phytopathol. Soc. Japan. 52, 225234.

18. Zeigler RS (1998) Recombination in Magnaporthe grisea. Ann. Rev. Phytopathol. 36, 249-275.

Table 1. Distribution of mating types of Finger millet isolates of Magnaporthe grisea collected from different locations

\begin{tabular}{|c|c|c|c|c|c|c|c|c|c|}
\hline \multirow[t]{2}{*}{ State } & \multicolumn{3}{|c|}{ Mating type } & \multicolumn{2}{|c|}{$\begin{array}{l}\text { Development of } \\
\text { perithecia }\end{array}$} & \multirow[t]{2}{*}{ Unknown } & \multirow[t]{2}{*}{ Total } & \multicolumn{2}{|c|}{$x^{2}$} \\
\hline & $\begin{array}{c}\text { Male } \\
\text { fertile }\end{array}$ & $\begin{array}{l}\text { Female } \\
\text { fertile }\end{array}$ & $\begin{array}{r}\text { Herma } \\
\text {-phrodite }\end{array}$ & $\begin{array}{c}\text { With } \\
\text { ascospore }\end{array}$ & $\begin{array}{c}\text { Without } \\
\text { ascospore }\end{array}$ & & & $\begin{array}{l}\text { Male fertile: } \\
\text { Female } \\
\text { fertile } \\
1: 1\end{array}$ & $\begin{array}{l}\text { Male fertile: } \\
\text { Female fertile: } \\
\text { Hermaphrodite } \\
1: 1: 1\end{array}$ \\
\hline \multicolumn{10}{|l|}{ North India } \\
\hline Uttarakhand & 45 & 31 & 27 & 87 & 16 & 51 & 154 & 2.56 & 5.197 \\
\hline Total & $(29.2)$ & $(20.1)$ & $(17.5)$ & $(56.4)$ & $(10.3)$ & $(33.1)$ & & & \\
\hline \multicolumn{10}{|l|}{ South India } \\
\hline Tamilnadu & 13 & 7 & 3 & 18 & 5 & 14 & 37 & & \\
\hline Karnataka & 10 & 10 & 0 & 16 & 4 & 18 & 38 & & \\
\hline Total & $\begin{array}{c}23 \\
(30.6)\end{array}$ & $\begin{array}{c}17 \\
(22.6)\end{array}$ & $\begin{array}{c}3 \\
(04.0)\end{array}$ & $\begin{array}{c}34 \\
(45.3)\end{array}$ & $\begin{array}{c}9 \\
(12.0)\end{array}$ & $\begin{array}{c}32 \\
42.6)\end{array}$ & 75 & 0.90 & $14.75^{\star *}$ \\
\hline Total & $\begin{array}{c}68 \\
(29.6)\end{array}$ & $\begin{array}{c}48 \\
(20.9)\end{array}$ & $\begin{array}{c}30 \\
(13.1)\end{array}$ & $\begin{array}{c}121 \\
(52.8)\end{array}$ & $\begin{array}{c}25 \\
(10.9)\end{array}$ & $\begin{array}{c}83 \\
(36.2)\end{array}$ & 229 & 3.44 & $14.85^{\star *}$ \\
\hline
\end{tabular}

Unknown isolates that failed to mate with any of the testers; Figures in parentheses express percent of mating type, ${ }^{* *}$ Calculated values do not fall under goodness of fit

Research article

CIndian Society for Education and Environment (iSee)
"Magnaporthe grisea" http://www.indjst.org
Srivastava et al. Indian J.Sci.Technol. 